\title{
Left Common Iliac Artery
}

National Cancer Institute

\section{Source}

National Cancer Institute. Left Common Iliac Artery. NCI Thesaurus. Code C32957.

The common iliac artery situated on the left side of the body. 